\title{
Psicología étnica y etnografía en Cataluña, un desarrollo cosmopolita ${ }^{1}$
}

\author{
Luis Calvo Calvo \\ Dpto. de Historia de la Ciencia. \\ Institución Milá y Fontanals. CSIC. Barcelona.
}

\section{RESUMEN}

Se ofrece una visión panorámica de la antropología catalana de comienzos del s. XX, destacando sus hitos teóricos y conceptuales alrededor de la psicología étnica y la obra de Tomás Carreras Artau. Se resaltan lo méritos internacionales de este desarrollo profesional, en coincidencia con la ciencia europea, y particularmente alemana e inglesa.

Palabras clave: Historia de la antropología, Psicología étnica, Carreras Artau, Batista Roca.

\section{SUMMARY}

In an overview of Catalan anthropology in the early $20^{\text {th }}$ century, the author emphasizes the theoretical and conceptual landmarks offered by Psicologia étnica and the work of Tomás Carreras Artau. This scholarly contribution, which achieved international recognition, matched contemporary developments of European science, especially in Germany and Britain.

Key words: Histoy of anthropolgy, Ethnical Psicology, Carreras Artau, Batista Roca.

\section{INTRODUCCIÓN}

El estudio de la implantación y del desarrollo de la psicología étnica en Cataluña, de hecho el único lugar de España donde se dio una experiencia de envergadura de este tipo de estudios a lo largo del siglo $\mathrm{xx}$, al menos con anterioridad al proceso de institucionalización de la disciplina -a partir de 1970 - , reviste una significativa importancia. La razón estriba en el hecho de que es un buen ejemplo del modo en que se implan-

${ }^{1}$ Este texto se presentó en el XIX Curso de Etnología Española sJulio Caro Baroja", que se tituló La construcción nacional de la Antropología. El factor foráneo, celebrado durante el mes de marzo de 1999, bajo la coordinación de Fermín del Pino.

RDTP, LVII, 2 (2002): 245-256 
taron en nuestro país algunas de las corrientes de pensamiento decimonónicas que contribuyeron, de manera significativa, a erigir la antropología como ciencia.

Antes de entrar propiamente en materia y en relación con el tema que ocupa el presente trabajo, con vistas a definir un marco general para nuestra argumentación, es necesario hacer mención de tres aspectos.

1. Las investigaciones sobre los orígenes de la antropología española. La denominada "psicología étnica" es uno de los más claros ejemplos de lo que el malogrado Alberto Cardín denominó como aintereses no tematizados": el discurso sobre el nacimiento y el desarrollo de nuestra antropología se ha centrado, casi de manera exclusiva, en la tradición folklórica, especialmente en la literatura oral. Es importante fijar nuestra atención en una serie de campos que no han gozado de una especial atención en la historiografía antropológica española, como el derecho (Terradas 1993; Del Pino 1996), la filosofía o la moral y la ética como "ciencias de las costumbres".

2. El manifiesto interés de gran número de autores del siglo XIX por aplicar los métodos positivos a todos los campos del conocimiento y de la experiencia humana. En este sentido, y a pesar de que adelanto reflexiones posteriores y en relación con este estudio, en los primeros años del siglo $\mathrm{xx}$, la psicología dio un giro substancial: se pasó de una concepción filosófica, deductiva y especulativa a una experimental, basada en lo inductivo. En el caso que nos ocupa, el Archivo de Etnografía y Folklore de Cataluña (AEFC), fue un buen ejemplo de ello: la recolección etnográfica fue el fundamento de la investigación psicológica (Carreras i Artau 1921: 51).

3. La preocupación decimonónica, presente también en las primeras décadas del siglo $\mathrm{xx}$, por conocer los aspectos más significativos de la mente humana. Dicha preocupación hizo que aquella fuese vista como auténtico motor de las formas sociales y culturales, lo que provocó buen número de declaraciones sobre el interés por establecer una auténtica genealogía de la civilización humana, como la que el propio Tomàs $\mathrm{Ca}$ rreras i Artau, fundador y director del AEFC, dejó escrita: “[...] elaborar una teoría sobre la génesis y el desarrollo de la cultura" (1923: 227).

Fijar nuestra atención en estos aspectos nos permitirá conocer los fundamentos de lo que fue la psicología étnica en la Cataluña de las primeras décadas del siglo Xx. En base a todo ello, se recurrirá a fuentes poco usuales en los estudios historiográficos españoles de carácter antropológico, fuentes que permitirán observar algo que, a mi juicio, no ha sido valorado suficientemente: el proyecto psico-etnográfico que se desarrolló en Cataluña se hizo, en buena medida, al unísono, o con una escasa diferencia de tiempo, con realizaciones foráneas similares. De hecho, y sal- 
vando las distancias, los escritos de Carreras i Artau sobre la importancia del estudio de la moral y de la ética como fuente de conocimiento psicológico y, a la vez, cultural fueron contemporáneos de los realizados por Lévy-Bruhl sobre estos mismos asuntos.

\section{FUENTES FORÁNEAS DE LOS ESTUDIOS DE PSICOLOGÍA ÉTNICA EN CATALUÑA}

Como ya se ha sugerido, el interés por conocer aspectos de la mente humana es uno de los primeros elementos clave en la nacimiento y el desarrollo de la psicología étnica en Cataluña; así, hay que tener presente que:

[...] dentro del marco teórico de fines del siglo xIx, centrado en el progreso, la razón, las leyes naturales y el determinismo, la Antropología Cultural nace interesada por explicar el origen, la evolución y el contraste entre las culturas, así como determinar la causa de las diferencias, raciales y culturales, entre los seres humanos. Por ello son frecuentes los conceptos relativos a la mente humana como, por ejemplo, el alma primitiva, la unidad psíquica, la consciencia colectiva, el inconsciente colectivo, la mentalidad pre-lógica y tantos otros (Buxó 1988: 159).

Esta inclinación por determinar la estructura de la mente humana fue fundamental en la institución que más y mejor formalizó en España su preocupación por estudiar los aspectos "culturales" de aquella: el AEFC y, más en concreto, en su fundador, Carreras i Artau. La predilección por este tema recibió un fuerte estímulo de los quehaceres que en estos asuntos llevaron a cabo algunos pensadores e instituciones foráneas, hasta el punto de que, con vistas a obtener conceptos y metodologías adecuadas, el AEFC envió a su secretario, Josep Maria Batista i Roca, a estudiar a la "escuela psico-etnográfica de Oxford", donde estudiosos como R. R. Marett llevaban a cabo su labor investigadora en este campo.

¿Cómo nacen los intereses de Carreras i Artau y del AEFC por estos temas? Sin entrar en detalles, ya expuestos en otros trabajos, hay un elemento que es básico en todo el proceso: Carreras i Artau era jurista de formación, lo que comportó que, desde joven, ya tuviese un vivo interés por todo lo relacionado con las formas de contratación, herencia, derecho familiar, etc.: es decir, por todo lo relacionado con la estructura social. De esta forma, la ética y la moral fueron vistas por él como auténticas ciencias de las costumbres y de los comportamientos, especialmente en su dimensión colectiva, aspecto que remite directamente a las fuentes foráneas más significativas que configuraron su pensamiento y su actuación: 
a) los filósofos moralistas escoceses y, por extensión, la filosofía anglosajona de tono empirista y su relación con la antropología;

b) la Volkerpsychologie de Wilhem Wundt;

c) los estudios de Lucien Lévy-Bruhl sobre la mentalidad primitiva.

Obsérvese que, a pesar de las diferencias entre estas corrientes, todas ellas tuvieron preocupaciones similares: en especial, en lo referido al estudio de la relación entre psicología y cultura, entre morfología social y representación colectiva. Veamos, con mayor detalle, cada una de ellas.

\section{A) La tradición filosófica anglosajona y la antropología británica}

En primer término, y sin remontarnos a autores del siglo XVII o de principios del siglo xviI, hay que recordar que algunos filósofos decimonónicos como Dugald Stewart, Frances Hutcheson o Thomas Reid insistieron - a través de la "filosofía del sentido común", luego desarrollada en España principalmente por Xavier Llorens i Barba, uno de los padres intelectuales de Carreras i Artau-, en la necesidad de que el estudio de la moral, entendida como conocimiento de las costumbres y de los hábitos de las sociedades, se debía objetivar al máximo, por lo que, frente a la deducción, se imponía la inducción.

Ello comportó, entre otras cosas, que la observación se convirtiese en un elemento de primer orden, circunstancia ésta que - tal como ha escrito Diego Núñez Ruiz (1975: 119)— supuso una significativa novedad en los planteamientos filosóficos generales del pasado siglo. Con todo, el inductivismo no llegó a formalizarse metodológicamente, como ocurrió más tarde con Malinowski y el desarrollo del trabajo de campo, aunque sí estimuló, en el caso del AEFC, una mayor aproximación al objeto de estudio, haciendo que la observación - aunque no incorporase la acepción de "participante" en todo su sentido- se convirtiese en uno de los ejes de sus trabajos. Esta situación explica el porqué del denodado interés de Carreras i Artau por la fotografía, como instrumento básico de investigación: había una fuerte creencia en la necesidad de salir a observar y a captar, de la manera más fiel posible, la realidad objeto de estudio.

Las tesis de los filósofos escoceses fueron recogidas, en gran medida, por otros autores británicos que, con el tiempo, tuvieron una importancia de primer orden en la configuración de los estudios antropológicos. En este sentido, no se puede obviar la importancia de John Stuart Mill y, sobre todo, del sexto libro de su A System of Logic Ratiocinative and Inductive (1843) que llevó como subtítulo "On the Logic of the Moral 
Sciences". Esta obra proporcionó, en primer término, algunas de las categorías a través de las cuales se forjó la antropología - especialmente la británica - como ciencia inductiva (Cardoso de Oliveira 1991b: 24); y, en segundo lugar, propició un encuentro más fructífero entre psicología y cultura. Así, en las argumentaciones de Mill, el método inductivo planteó que todo fenómeno o circunstancia tiene una causa, hecho que solamente se puede comprender a través de la experiencia. De hecho, ésta se presentó como la clave de bóveda de diferentes disciplinas - por ejemplo, las ciencias morales- que tenían como eje el estudio del comportamiento humano a través de la observación, por simple que ésta fuese.

Este tipo de reflexiones hicieron que, a la larga, sus argumentaciones se constituyesen en un referente para las ciencias sociales y, sobre todo, para la antropología. En este sentido se ha escrito que: "el psicologismo inherente a la obra de Mill forma parte de la tradición empirista británica [...] su doctrina nutre las nociones básicas que marcarán la episteme de final del siglo XIX e inicios del XX" (Cardoso de Oliveira 1991a: 29), reflexión que permite comprender mucho mejor el interés de diversos estudiosos ingleses de la citada época por desgranar la relación entre psicología y cultura. Así, cabe traer aquí a colación las aseveraciones de Paul Mercier, al referirse a las preocupaciones que sobre tales temas se suscitaron en la antropología británica de principios del siglo xx:

[...] al mismo tiempo que en los Estados Unidos, C.G. Seligman en Gran Bretaña y M. Mauss en Francia presentan la importancia de los estudios psico-antropológicos [...] investigaciones relativas a las relaciones entre la cultura y la personalidad, en los patterns culturales (Mercier 1977: 72).

Entre los estudiosos que recogieron las orientaciones de Mill, hay que destacar a W. H. R. Rivers y R. R. Marett, que trabajaron a lo largo de su carrera por conciliar antropología y psicología. Así, el primero escribió que:

Si la necesidad del análisis etnológico de la cultura fuese reconocida, el estudio psicológico se volvería más complicado y difícil de lo que fuera en el pasado, pero no por ello se volvería menos esencial. Junto con el análisis etnológico, se precisa ir a las profundidades de los modos de pensar de los pueblos, para comprender sus modos de ver y de clasificar los hechos del universo. Y solamente por la combinación de análisis etnológico y psicológico podremos realizar un avance real (Rivers 1911; citado por Cardoso de Oliveira 1991b: 166-167).

Como se puede ver, la dimensión psicológica es un elemento fundamental en su visión, hasta el punto que Gordon Elliot Smith, en el prefacio que escribió para la obra póstuma de Rivers, Psychology and Ethnology (1926: IX), dijo que: 
Una simple colección y tabulación de datos [...] no eran sus reales intereses, sino únicamente una preparación esencial para la investigación de los problemas psicológicos que se alojan en el corazón de la Etnología. Una interpretación de las prácticas sociales, creencias y costumbres fue para él más un medio de abordar los procesos mentales que estaban implicados. Los pensamientos y comportamientos de cualquier comunidad eran merecedores de estudio como un medio de entender la psicología de la humanidad como un todo. Para el Dr. Rivers, que fue primero psicólogo y después un etnólogo, todo problema en etnología era esencialmente psicológico.

Hay que señalar que frente a otras tradiciones de carácter antropológico (caso de Francia con Durkheim y el racionalismo francés), esta imbricación entre psicología y etnología respondía, en el ánimo de Rivers, a una visión de carácter holístico, donde participaba, tanto la antropología, la filología y la antropología física como la historia; en este sentido, es interesante releer su última conferencia "The unity of Anthropology" (1922).

Esta corriente de pensamiento fue clave en el desarrollo de los trabajos del AEFC, hasta el punto de que - como ya se apuntó- el secretario de la entidad, J. M. Batista i Roca, se desplazó durante el curso 19191920 a Oxford -en concreto a la denominada por Carreras i Artau uescuela psico-antropológica de Oxfordn- para formarse en tales cuestiones con antropólogos de la talla de Haddon o Marett (Calvo 1987: 103-111). Así reconocía el propio Batista i Roca la importancia de tales estudios en Gran Bretaña:

[...] els etnógrafs anglesos - ells prefereixen dir-se antropòlegs- estan fondament dividits en dues escoles principals, la psicológica y la històrica o propiament etnogràfica [...] l'escola psicológica -defensada principalment pel meu professor Dr. R.R. Marett- sosté q. la identitat de costums en pobles diferents no mostra la identitat del esperit humà, q. davant d'iguals excitants reacciona sempre igualment. Seguint al psicòleg alemany Freud, dona molta importancia a lo inconscient per explicar l'origen dels mites y llegendes, q. aquestes en lo social son figures del mateix tipus q. els somnis en l'individu ${ }^{2}$.

Estas reflexiones vinieron a enlazar con lo que en el seno del AEFC, desde hacía años, se estaba estudiando. De esta forma, el mismo Batista i Roca ya había escrito en 1918 que:

[...] si la Etnografia recull i estudia les manifestacions més espontànees i primitives de la cultura d'un poble, no cal gaire esforç per mostrar la importància d'aquesta ciència per aportar materials en què fonamentar l'estudi de la Psicologia d'aquest poble (Batista i Roca 1918: 102).

2 J. M. Batista i Roca, Exeter College, Oxford, 24 de enero de 1920. Archivo AEFC, Institución Milá y Fontanals, CSIC. Barcelona. La transcripción es fiel a la ortografía original. 


\section{B) La psicología de los pueblos}

La segunda gran influencia citada, la Volkerpsychologie de Wilhem Wundt, tiene sus antecedentes en los trabajos de Lazarus, Stenthal y otros autores del siglo XIX preocupados por todo lo relativo al estudio de las colectividades. A pesar de sus iniciales conexiones con el movimiento romántico - $\mathrm{y}$ con todo lo relacionado con el Volksgeist herderiano-, Wundt, con su acusado experimentalismo, redimensionó los trabajos de aquéllos. En este sentido, Wundt, además de iniciar la investigación en psicología experimental, abogó por una segunda vía de análisis de la realidad: la denominada por él psicología de los pueblos (Völkerpsychologie), que fue de hecho uno más de los intentos decimonónicos por establecer y explicitar la historia cultural humana. Con el paso del tiempo la primera de las corrientes fue la que se impuso, quedando cada vez más arrinconada y olvidada la segunda, esencialmente a causa de la irrupción de las teorías psicoanalíticas y de la dificultad de categorizar los fenómenos psicológicos de carácter colectivo.

Entre los distintos objetivos que perseguía Wundt con su Volkerpsychologie, uno de los que más tuvo influencia en Carreras i Artau fue su preocupación por realizar, a través de la psicología de los pueblos, la historia del desarrollo psíquico de la Humanidad (Wundt 1926), que fue dividido en cuatro grandes estadios: hombre primitivo, totemístico, héroes y dioses, evolución hacia la Humanidad. Dicha categorización le hizo considerar que el concepto de "primitivo" debía entenderse en sentido relativo, en cuanto representaba el ínfimo grado de la cultura, especialmente de la espiritual (Anónimo 1930: 476).

Este conjunto de ideas fue recogido por Carreras i Artau, hasta el punto de que algunas de sus argumentaciones eran plasmación directa de las expresadas por Wundt; así, al hablar de los objetivos del AEFC, Carreras i Artau declaró que el fin último era:

[...] reconstituir, fins on sigui possible, el procés de desenrotllament mental en l'home prehistòric, en el salvatge, en l'home folklòric i en l'infant respectivament, amb la doble finalitat de cotejar els resultats i veure si existeix un fons comú que permeti afirmar la unitat d'aquelles quatre mentalitats (1923: 219).

Tales planteamientos —origen e historia del psiquismo humano, diferenciación de mentalidades y comportamientos, grados y estadios de civilización, etc.- fueron uno de los pilares del trabajo de Carreras i Artau, quien de hecho se preocupó por conjugar las dos líneas de investigación wundtiana, intentando desarrollar ambas a la par, tal como se puede apreciar si se repasa su trayectoria científica (Calvo 1994). 


\section{C) Lucien Lévy-Brubl y la mentalidad primitiva}

Los planteamientos teóricos de Carreras i Artau sobre la mentalidad étnica se articularon con el nombre de "psico-etnografía", que se nutrió, junto con los dos aspectos hasta ahora citados, de las tesis del filósofo francés Lucien Lévy-Bruhl sobre las mentalidades.

Con respecto a este autor ${ }^{3}$, hay que señalar, en primer lugar, que sus trabajos buscaron extender la aplicación del método positivo, sobre todo, con vistas a equilibrar el peso del pensamiento especulativo (Cardoso de Oliveira 1991a: 4) que, en aquellos momentos, seguía teniendo un protagonismo de primer orden; así, y con vistas a favorecer el desarrollo de una "ciencia de las costumbres", Lévy-Bruhl apostó por dicho método como instrumento para caracterizar los fenómenos morales o sociales, lo que respondió al intento de "positivizar el conocimiento" (Cardoso de Oliveira 1991a: 13). Tal opción conllevó, por ejemplo, que determinados aspectos de la conciencia o de la percepción humanas, en el caso de la intuición o del sentimiento, empezasen a ser vistos como susceptibles de conocimiento directo e inmediato, en oposición a los conocimientos de carácter discursivo (Ibid: 15), aspecto que, en otro orden de cosas, la filosofía escocesa del sentido común de los siglos XVIII y XIX ya había apuntado, filosofía estudiada y llevada a sus últimas consecuencias por Carreras i Artau.

Una buena muestra de las anteriores aseveraciones se encuentra en las reflexiones que Lévy-Bruhl realizó al referirse a los sentimientos, coincidiendo en buena medida con lo que ya se ha indicado sobre Mill y Rivers: “[...] los estados afectivos que acompañan a las ideas se hallan determinados socialmente [...] por tanto, la mentalidad de un pueblo es algo objetivo. Si se tratara tan sólo de un fenómeno individual, sería subjetivo; es objetivo por lo que tiene de general" (Evans Pritchard 1979: 136). En el mismo sentido, Lévy-Bruhl se apercibió, en un esfuerzo denodado por intentar objetivizar todo lo relacionado con la moral de las sociedades, de que: "[...] los valores forman sistemas tan coherentes como las construcciones lógicas del intelecto, que existe una lógica de los sentimientos paralela a la de la razón aunque basada en un principio distinto" (Ibid: 141).

Estas reflexiones y otras similares constituyeron, en buena medida, los pilares de sus estudios sobre el pensamiento primitivo, siendo el primero de ellos La Morale et la science des moeurs (1903). ¿Por qué esta preocu-

3 Véanse, además de la citada obra de Cardoso de Oliveira (1991a), entre otros, Cazeneuve (1963), Lévy-Bruhl (1988) y Goldman (1998). 
pación por "la ciencia de las costumbres"? Éste es un aspecto interesante en su trayectoria, ya que surgió en él, al igual que en otros estudiosos como es el caso de Comte, a partir del interés por ofrecer teorías que permitiesen una reordenación del mundo moral y político, alterado por las transformaciones producidas por la Revolución Industrial y los cambios socio-políticos que Europa vivió a lo largo del siglo XIX. De hecho, recuérdese que uno de los grandes objetivos de Comte fue: «[...] interferir en el orden social a través del establecimiento de principios que propicien una 'reorganización social'" (Cardoso de Oliveira 1991a: 6). Para ello era necesario elaborar una ciencia de las costumbres que diera cuenta de los hechos morales de la sociedad: se pensaba que el "desorden moral y mental" era una de las causas fundamentales de la situación de "enfermedad occidental" que aquejaba a nuestra civilización (Ibid: 7-8). Lévy-Bruhl se planteó, en definitiva, que una reorganización de la sociedad solamente podía pasar por un reorganización de las costumbres, para lo cual era necesario catalogarlas, analizarlas y objetivizarlas previamente.

Sin embargo, a diferencia de los científicos sociales anglosajones, LévyBruhl abordó tales problemáticas desde posturas iniciales diferentes; así, y como señaló Evans Pritchard (1979: 131), mientras que aquéllos estudiaban:

[...] los hechos sociales partiendo de procesos de pensamiento individual [...] [LévyBruhl consideró que] [...] la mentalidad del individuo procede de las representaciones colectivas de su sociedad, [...] son obligatorias, y estas representaciones son función de las instituciones. Consiguientemente, ciertos tipos de representaciones, y por tanto ciertos modos de pensar, pertenecen a determinados tipos de estructura social [...] cada tipo de sociedad tiene por lo tanto una mentalidad característica, pues cada uno tiene costumbres e instituciones características.

De hecho —y como ha indicado Marcio Goldman (1998)—, Lévy-Bruhl, sintonizando en gran medida con los sociólogos franceses del momento, intentó establecer la relación entre morfología social y representaciones colectivas, aspecto que, en el caso del AEFC, también se intentó llevar a cabo (Calvo 1991: 94-104).

Los trabajos de Lévy-Bruhl sobre este tema buscaron, y esta fue otra novedad en su momento, analizar más las diferencias que las semejanzas, como se había hecho hasta aquel momento. Ello, junto con lo que se ha apuntado sobre la visión colectiva de las realidades psico-culturales, hizo que definiese la "mentalidad primitiva" como "prelógica y mística", lo que comportó una valoración negativa de tales planteamientos por parte de la antropología anglosajona. Tales críticas -a excepción de las reflexiones de Evans Pritchard - no tuvieron en cuenta el sentido que el autor francés atribuía a dichos términos; así, por "prelógico" entendió no tanto 
"alógico" o "antilógico", como señala Evans Pritchard (1934: 134-135), sino que su "[...] concepción del universo no es crítica y científica [...] por 'prelógico' apenas entiende otra cosa que acientífico o acrítico". A pesar de ello, Lévy-Bruhl presentó a las culturas o pueblos "primitivos" más supersticiosos de lo que eran en realidad y a la civilización occidental más positivista de lo que realmente era (Evans Pritchard 1934: 148), aspectos que al final de su vida corrigió.

Este tipo de reflexiones fueron rápidamente asimiladas por Carreras i Artau, hasta el punto de que escribió que:

La mentalitat primitiva, quan es desenrotlla normalment, es manifesta amb un seguit de productes, no certament de classe superior ni inferior si se'ls compara amb els productes consemblants de les societats civilitzades, sinó diferents, ben propis, sui generis, gairebé sempre caracteritzats per una ingènua i forta originalitat [...] I sols es pot parlar pròpiament de productes inferiors, però -noti's bé- en comparació amb les manifestacions normals de la mateixa mentalitat primitiva, no en oposició als productes de les societats civilitzades (Carreras i Artau 1923: 215).

Como se puede ver, las mismas ideas de Lévy-Bruhl —objetivación de ideas y de sentimientos - sirvieron de base a Carreras i Artau para construir sus teorías sobre la mentalidad primitiva ${ }^{4}$ que fue vista por él como: “....] conjunt de disposicions intellectuals, de tendències afectives i de creences fonamentals que són el punt de partida d'un procés de cultura" (1923: 219); definición en la que se puede apreciar cómo buscó poder captar y recopilar, para su tratamiento posterior sentimientos, ideas y creencias.

Más allá de los datos que aquí se ofrecen, creo que, una vez más - y tal como se viene abogando desde hace tiempo por distintos profesionales- las referencias que hasta aquí se han señalado ponen en un claro entredicho el tan traído y llevado tópico sobre un cierto "provincialismo" u "autoctonismo" en la construcción de nuestra antropología. Los trabajos del AEFC y de Carreras i Artau son un ejemplo más de cómo el tópico del aislamiento intelectual no se dio, ni con mucho, en nuestra antropología. Lo que debería tal vez ser motivo de una más seria reflexión colectiva.

\footnotetext{
${ }^{4}$ Junto a los estudios ya mencionados, "Psicología del poble català" (1921) y “Estudis de Psicologia ètnica; el concepte de 'Mentalitat Primitiva'" (1923), Carreras i Artau expuso sus ideas sobre el particular en la ponencia que presentó en el Congreso de la Asociación Española para el Progreso de la Ciencias, celebrado en Barcelona en 1929: "Problemas actuales de la Psicología colectiva y étnica y su trascendencia filosófica".
} 


\section{BIBLIOGRAFÍA CITADA}

ANÓNIMO. 1930. "W. Wundt". Enciclopedia Espasa LXX. Bilbao: Espasa.

BATISTA I ROCA, J. M. 1918. "Els materials etnogràfics i l'excursionisme". Excursions 34: 102.

Buxó, M. J. 1988. "Cognición”, en Ángel Aguirre (ed.), Diccionario temático de Antropología: 159-164. Barcelona: PPU.

Calvo, L. 1987. "Viaje de formación de un etnólogo catalán (1919-1920)". Anthropológica 2: 103-111.

- 1991. El "Arxiu d'Etnografia i Folklore de Catalunya" y la antropología catalana. Barcelona: CSIC

- 1992. "Tomàs Carreras Artau y la Psicoetnografía. El primer antecedente de la Etnopsicología en Españan. Anuario de bistoria de la antropología española 1: 2737.

- 1994. Tomás Carreras i Artau o el tremp de l'etnologia catalana. Barcelona: Publicacions de l'Abadia de Montserrat.

CARDoso DE Oliveira, R. 1991a. Razão e Afetividade. O pensamento de Lucien LévyBrubl. Campinas: UNICAMP.

- (ed.) 1991b. A antropologia de Rivers. Campinas: UNICAMP.

CARRERAS I ARTAU, T. 1921. "Psicologia del poble català". Manual per a recerques d'etnografia de Catalunya: 51-74. Barcelona: AEFC.

- 1923. "Estudis de Psicologia ètnica; el concepte de 'Mentalitat Primitiva'. Anuari de la Societat Catalana de Filosofia I: 213-228.

- 1929. "Problemas actuales de la Psicología colectiva y étnica y su trascendencia filosófica". Madrid: Asociación Española para el Progreso de las Ciencias, Imp. Huelves y Cia. 1: 58-88.

Cazeneuve, J. 1963. Lucien Lévy-Brubl. París: PUF.

Del PINo, F. 1996. “¿Abogado o antropólogo? La obra etnológica de Joaquín Costa y su pluralidad disciplinar y contextual", en VII Congreso de Antropología. Simposio I: 23-53. Zaragoza: Federación de Asociaciones de Antropología del Estado Español, Instituto Aragonés de Antropología.

EvANS PRITCHARD, E. E. 1934. "Lévy-Bruhl's Theory of Primitive Mentality". Bulletin of the Faculty of Arts. El Cairo: 134-135.

- 1979. Las teorías de la religión primitiva. Madrid: Siglo XXI.

Goldman, M. 1998. "Raison et Différence. À propos de Lucien Lévy-Bruhl". Gradhiva 23: $1-21$.

LÉVY-Bruhl, L. 1988. Carnets. París: Quadrige/PUF.

Mercier, P. 1977. Historia de la Antropología. Barcelona: Península.

NúNEZ RUIZ, D. 1975. La mentalidad positiva en España: desarrollo y crisis. Madrid: Túcar Ediciones.

RIVERS, W. H. R. 1911. "Un análisis etnológico de la cultura". Comunicación presidencial para la Sección Antropológica de la Asociación Británica para el Progreso de las Ciencias.

TERradAS, I. 1993. "La Historia del Derecho de Cataluña de Guillem de Brocà. Una obra cabdal per a la història i l'Antropologia Social dels catalans". El Europeo 1: 29-34. 
WUNDT, W. 1926. Elementos de psicología de los pueblos [Bosquejo de una bistoria de la evolución psicológica de la Humanidad]. Trad. Santos Rubiano. Madrid: Daniel Jorro. 